\title{
Mesenteric Vessel Thrombosis Treatment Experience
}

\author{
Vladimir Beloborodov ${ }^{1}$, Vladimir Vorobev ${ }^{1 *}$ D, Svetlana Sokolova ${ }^{1}$, Aleksandr Frolov$^{1}$, Denis Kornilov ${ }^{2}$, Ludmila Sorokina ${ }^{1}$, \\ Igor Golub ${ }^{1}$ \\ ${ }^{1}$ Department of General Surgery and Anesthesiology, Irkutsk State Medical University, Irkutsk, Russia; ${ }^{2}$ Department of \\ Traumatology, Orthopedics and Neurosurgery, ISMAPgE - Branch Campus of the FSBEI FPE RMACPE MOH Russia, \\ Irkutsk, Russia
}

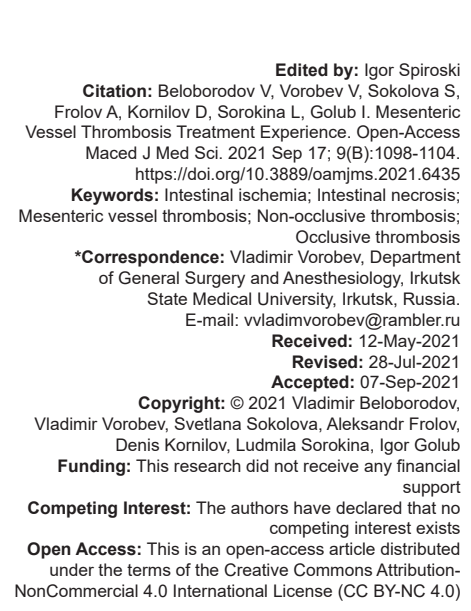

\section{Introduction}

One of the most serious diseases among all emergency abdominal pathologies is an acute violation of the mesenteric blood circulation. The rapid development of intestinal ischemia leads to its infarction and necrosis [1]. According to Russian clinical guidelines, acute mesenteric ischemia (AMI) manifests in a partial or complete cessation of arterial or venous blood flow within the mesenteric circulation [2].

The number of patients with this pathology increases annually because of the growing number of elderly and senile people, as well as cardiovascular pathology [1], [3]. Acute violation of mesenteric circulation varies from $0.09 \%$ to $0.2 \%$ in the structure of all urgent abdominal pathology [3]. The average age of patients with this pathology is around 70 years old [4]. There are no gender differences in the incidence of the disease [1]. According to additional studies, most often the disease affects the superior mesenteric artery (up to 90\%) [5].

In surgical practice, there are occlusive and non-occlusive forms of mesenteric vascular lesions. Occlusive forms include mesenteric artery embolism
AMI (up to $50 \%$ of cases), mesenteric artery thrombosis thrombotic AMI (15-25\%), and mesenteric vein thrombosis AMI (5-15\%). Non-occlusive mesenteric ischemia is relatively rare (5-20\%) [6].

The disease manifests in various and nonspecific ways, a latent course complicates the diagnosis verification [3]. Irreversible changes occur quickly especially in the case of occlusion, which gives a terribly poor prognosis for life and recovery [7]. The most reliable diagnostic techniques are various mesenteric vessels examining, such as angiography, allowing in some cases at the same time remove a thrombus [3]. The main treatment goal is to restore vascular patency or remove non-viable intestinal segments and correct complications [3]. The study aims to compare the results of mesenteric vascular thrombosis treatment.

\section{Methods}

The local ethical committees of the Federal State Budgetary Educational Institution of Higher 
Education "Irkutsk State Medical University" of the Ministry of Health of the Russian Federation and the Regional State Budgetary Institution of Healthcare "Irkutsk Clinical Hospital No. 1" approved the clinical trial. The retrospective study took place at the surgical department of the Irkutsk Clinical Hospital No. 1.

The clinical part of the study includes an analysis of the examination and treatment results (surgical and/ or conservative) of patients with mesenteric thrombosis for 2016-2019. follows:

The inclusion criteria for the study are as

1. Confirmed thrombosis of mesenteric vessels

2. The completed required examination

3. Multi-slice computed tomography (MSCT) angiography with a verified diagnosis before the operation

4. The patient is over 18 years old.

The patient underwent surgical treatment (thromboembolectomy or intestinal resection), or observational laparotomy/laparoscopy established inoperable resultand/or the patient underwent conservative treatment according to the presented scheme.

Non-inclusion criteria are as follows:

1. Thrombosis of the celiac trunk vessels

2. Absence of mesenteric vessels thrombosis

3. The patient did not complete the required examination.

Due to various reasons, the patient did not meet the treatment standard or underwent another operation that did not meet the group's criteria.

\section{Patient involvement}

Patients were they intimately involved in design and implementation of the intervention. Patients were also central to dissemination of the baseline information, which helped to motivate community involvement during and beyond the study.

\section{Study group characteristics}

The study presents a retrospective analysis of clinical cases with an established diagnosis of mesenteric vascular thrombosis from 2016 to 2019. During this period, there were 147 patients with an established diagnosis of mesenteric thrombosis. Only 21 patients met the study criteria. The patients had either occlusive (Group I, $\mathrm{n}=11$ ) or non-occlusive thrombosis (Group II, $n=10$ ) of mesenteric vessels.

\section{Analysis/diagnostic and treatment methods}

The obligatory examination included complaints and anamnesis, physical examination, clinical blood, and urine tests, biochemical blood test, coagulogram indices, blood electrolyte analysis, the ultrasound, and X-ray of the abdominal organs, and MSCT angiography.

Surgical treatment included laparotomy, thromboembolectomy, and/or bowel resection. Conservative therapy included correction of waterelectrolyte disturbances, anticoagulant therapy (heparin), with vasoactive, antioxidant, anti-enzyme, and antibacterial drugs.

\section{Data analysis}

The authors used STATISTICA for Windows 10.0 (Statsoft, Inc., USA), SPSS Statistics 23.0 (IBM, USA), and Stata 14.2 (StataCorp, USA) to analyze the initial data and surgical treatment results. There were two groups to compare the examination and surgical treatment results: Group I and Group II.

\section{Perioperative period}

All patients before and after surgical treatment stayed in the intensive care unit. The authors assessed treatment results within 6 months after the hospitalization and considered the case as relapse free if there was no repeated treatment.

\section{Results}

\section{Pre-operative parameters}

The average age of patients in study groups was $77.2 \pm 8.8$ and $76.9 \pm 8.1$, respectively ( $p=0.921)$. In both groups, women predominated: Four men $(36.3 \%)$ in the first group and $3(30 \%)$ in the second group $(p=0.826)$. The median duration of the disease was $24(10 ; 72)$ and $20(4$; 24) $h$, respectively, and did not differ significantly $(p=0.597)$. Among those who applied with intestinal circulatory disorders at the ischemic stage (the first $6 \mathrm{~h}$ of the disease, without signs of necrosis), $2(18.1 \%)$ patients were from Group I, and $4(40 \%)$ were from Group II ( $p=0.410)$.

Table 1 presents the pre-operative parameters of patients.

Table 2 presents the characteristics of complaints and examination data.

Only $2(18.1 \%)$ patients of Group I had peritoneal symptoms, no cases in the second group ( $p=0.194)$. X-ray data showed signs of acute intestinal obstruction for $3(27.2 \%)$ patients of Group I and $1(10 \%)$ patient of Group II ( $p=0.403)$, ultrasound confirmed $1(9 \%)$ case of Group I and no cases of 
Group II ( $p=0.350)$. The examination detected acute gastritis for $6(54.5 \%)$ patients of Group I and 4 (40\%) patients of Group II ( $p=0.690)$, including erosive gastritis in $1(9 \%)$ case of Group I and 1 (10\%) case of Group II ( $p=0.948)$. Only $1(9 \%)$ patient of Group I had an acute gastric ulcer, no cases in the second group $(p=0.350)$.

Table 1: Pre-operative parameters of patients in comparison groups

\begin{tabular}{llll}
\hline Parameter & Group I $(\mathrm{n}=11)$ & Group II $(\mathrm{n}=10)$ & $\mathrm{p}$ \\
\hline Height, $\mathrm{cm}$ & $165.7 \pm 8.8$ & $168.1 \pm 8.1$ & 0.921 \\
Weight, kg & $71.7 \pm 6.1$ & $83.7 \pm 15.8$ & 0.030 \\
Smoking, $\mathrm{n}(\%)$ & $1(9)$ & $0(0)$ & 0.350 \\
Previous myocardial infarction, $\mathrm{n}(\%)$ & $2(18.1)$ & $3(30)$ & 0.618 \\
Previous stroke, $\mathrm{n}(\%)$ & $2(18.1)$ & $4(40)$ & 0.410 \\
Vascular atherosclerosis, $\mathrm{n}(\%)$ & $9(81.8)$ & $10(100)$ & 0.751 \\
Heart rhythm disturbances, $\mathrm{n}(\%)$ & $7(63.6)$ & $7(70)$ & 0.890 \\
Essential hypertension, $\mathrm{n}(\%)$ & $11(100)$ & $10(100)$ & 1.000 \\
Peptic ulcer, $\mathrm{n}(\%)$ & $1(9)$ & $0(0)$ & 0.350 \\
Diabetes, $\mathrm{n}(\%)$ & $2(18.1)$ & $5(50)$ & 0.274 \\
Chronic cholecystitis, $\mathrm{n}(\%)$ & $1(9)$ & $0(0)$ & 0.350 \\
Chronic pyelonephritis, $\mathrm{n}(\%)$ & $1(9)$ & $0(0)$ & 0.350 \\
Urolithiasis, $\mathrm{n}(\%)$ & $1(9)$ & $1(10)$ & 0.948 \\
Erythrocytosis, $\mathrm{n}(\%)$ & $6(54.5)$ & $3(30)$ & 0.469 \\
Erythropenia, $\mathrm{n}(\%)$ & $1(9)$ & $0(0)$ & 0.350 \\
Anemia, $\mathrm{n}(\%)$ & $1(9)$ & $0(0)$ & 0.350 \\
Blood thickening of, $\mathrm{n}(\%)$ & $9(81.8)$ & $6(60)$ & 0.650 \\
Leukocytosis, $\mathrm{n}(\%)$ & $11(100)$ & $9(90)$ & 0.866 \\
Coagulopathy, $\mathrm{n}(\%)$ & $9(81.8)$ & $6(60)$ & 0.650 \\
Proteinuria, $\mathrm{n}(\%)$ & $8(72.7)$ & $4(40)$ & 0.948 \\
Leukocyturia, $\mathrm{n}(\%)$ & $11(100)$ & $10(100)$ & 1.000 \\
Hyperglycemia, $\mathrm{n} \mathrm{( \% )}$ & $8(72.7)$ & $8(80)$ & 0.885 \\
Hyperamylasemia, $\mathrm{n}(\%)$ & $3(27.2)$ & $2(20)$ & 0.758 \\
Hypoamylasemia, $\mathrm{n}(\%)$ & $4(36.3)$ & $0(0)$ & 0.074 \\
Hypokalemia, $\mathrm{n}(\%)$ & $5(45.4)$ & $5(50)$ & 0.901 \\
Hyponatremia, $\mathrm{n}(\%)$ & $1(9)$ & $2(20)$ & 0.537 \\
Hypernatremia, $\mathrm{n}(\%)$ & $3(27.2)$ & $0(0)$ & 0.117 \\
Hypochloremia, $\mathrm{n}(\%)$ & $4(36.3)$ & $1(10)$ & 0.261 \\
Hypocalcemia, $\mathrm{n}(\%)$ & $5(45.4)$ & $7(70)$ & 0.553 \\
Hypercalcemia, $\mathrm{n}(\%)$ & $2(18.1)$ & $0(0)$ & 0.194 \\
\hline
\end{tabular}

Anamnestic data analysis revealed that 5 patients $(45.4 \%)$ of the first group and 4 patients $(40 \%)$ of the second group $(p=0.873)$ underwent previous surgical treatment on the abdominal organs. Table 3 shows the results of MSCT angiography in the comparison groups.

Table 2: Characteristics of complaints and examination data

\begin{tabular}{|c|c|c|c|}
\hline Parameter & Group I $(n=11)$ & Group II $(n=10)$ & $p$ \\
\hline \multicolumn{4}{|l|}{ Complaints } \\
\hline Abdominal pain, $\mathrm{n}(\%)$ & $11(100)$ & $8(80)$ & 0.726 \\
\hline Spilled pains, $n(\%)$ & $71.7 \pm 6.1$ & $83.7 \pm 15.8$ & 0.332 \\
\hline Epigastric pain, n (\%) & $2(18.1)$ & $2(20)$ & 0.930 \\
\hline Pain in the mesogastrium, $\mathrm{n}(\%)$ & $1(9)$ & $1(10)$ & 0.948 \\
\hline Hypogastric pain, $n(\%)$ & $0(0)$ & $2(20)$ & 0.156 \\
\hline Nausea, n (\%) & $8(72.7)$ & $4(40)$ & 0.751 \\
\hline Vomiting, n (\%) & 7 (63.6) & $3(30)$ & 0.352 \\
\hline Stool retention, $\mathrm{n}(\%)$ & $1(9)$ & $0(0)$ & 0.350 \\
\hline Weakness, n (\%) & $5(45.4)$ & $4(40)$ & 0.873 \\
\hline Diarrhea, n (\%) & $0(0)$ & $2(20)$ & 0.156 \\
\hline \multicolumn{4}{|l|}{ Objective status } \\
\hline Bloating, n (\%) & $1(9)$ & $0(0)$ & 0.350 \\
\hline Abdomen asymmetry, $\mathrm{n}(\%)$ & $1(9)$ & $0(0)$ & 0.350 \\
\hline Tenderness to palpation, $\mathrm{n}(\%)$ & $10(90.9)$ & $7(70)$ & 0.691 \\
\hline $\begin{array}{l}\text { Tenderness to palpation in the epigastrium, } \\
\mathrm{n}(\%)\end{array}$ & $5(45.4)$ & $4(40)$ & 0.873 \\
\hline $\begin{array}{l}\text { Tenderness to palpation in the } \\
\text { mesogastrium, } \mathrm{n}(\%)\end{array}$ & $2(18.1)$ & $1(10)$ & 0.642 \\
\hline $\begin{array}{l}\text { Tenderness to palpation in hypogastrium, } \\
\mathrm{n}(\%)\end{array}$ & $2(18.1)$ & $2(20)$ & 0.930 \\
\hline $\begin{array}{l}\text { Muscle tension of the anterior abdominal } \\
\text { wall, } n(\%)\end{array}$ & $2(18.1)$ & $0(0)$ & 0.194 \\
\hline The abdomen is enlarged, $\mathrm{n}(\%)$ & $5(45.4)$ & $4(40)$ & 0.873 \\
\hline
\end{tabular}

Thus, the analysis of the main characteristics of the comparison groups established relative comparability $(p>0.05)$.
Table 3: MSCT angiography results

\begin{tabular}{|c|c|c|c|}
\hline Indicator & Group I $(n=11)$ & Group II $(n=10)$ & $\mathrm{p}$ \\
\hline Ischemia zone, ileum, n (\%) & $9(81.8)$ & $8(80)$ & 0.972 \\
\hline Ischemia zone, jejunum, $\mathrm{n}(\%)$ & $8(72.7)$ & $8(80)$ & 0.885 \\
\hline Ischemia zone, cecum, $\mathrm{n}(\%)$. & $4(36.3)$ & $0(0)$ & 0.074 \\
\hline Ischemia zone, ascending gut, n (\%) & $4(36.3)$ & $0(0)$ & 0.074 \\
\hline Ischemia zone, transverse colon, $\mathrm{n}(\%)$ & $1(9)$ & $0(0)$ & 0.350 \\
\hline Ischemia zone, descending intestine, $n(\%)$ & $1(9)$ & $0(0)$ & 0.350 \\
\hline Ischemia zone, sigmoid and rectum, $n(\%)$ & $1(9)$ & $0(0)$ & 0.350 \\
\hline $\begin{array}{l}\text { Thrombosis localization, superior } \\
\text { mesenteric artery, } \mathrm{n}(\%)\end{array}$ & $11(100)$ & $8(80)$ & 0.726 \\
\hline $\begin{array}{l}\text { Thrombosis localization, superior } \\
\text { mesenteric artery, } 1^{\text {st }} \text { segment, } \mathrm{n}(\%)\end{array}$ & $1(9)$ & $5(50)$ & 0.120 \\
\hline $\begin{array}{l}\text { Thrombosis localization, superior } \\
\text { mesenteric artery, } 2^{\text {nd }} \text { segment, } n(\%)\end{array}$ & $5(45.4)$ & $3(30)$ & 0.624 \\
\hline $\begin{array}{l}\text { Thrombosis localization, superior } \\
\text { mesenteric artery, } 3^{\text {rd }} \text { segment, } n(\%)\end{array}$ & $5(45.4)$ & $3(30)$ & 0.624 \\
\hline $\begin{array}{l}\text { Thrombosis localization, inferior mesenteric } \\
\text { artery, } \mathrm{n}(\%)\end{array}$ & $0(0)$ & $2(20)$ & 0.156 \\
\hline Occlusion degree, $\%$ & 100 & $59.5 \pm 24.9$ & $<0.0001$ \\
\hline
\end{tabular}

MSCT: Multi-slice computed tomography.

\section{Treatment results}

To assess the treatment results of occlusive (Group I) and non-occlusive (Group II) mesenteric vessel thrombosis, the authors analyzed the outcomes and performed differential analysis depending on the chosen surgical tactics.

There were $4(36.3 \%)$ recovered patients in the first group and $7(70 \%)$ patients in the second group ( $p=0.388)$. The rest of the patients died. Three $(27.2 \%)$ patients of Group I and $4(40 \%)$ patients of Group II $(p=0.662)$ received only conservative therapy, two of them $(66.6 \%$, Group I) and 4 (100\%, Group II) noted recovery $(p=0.724)$. The overall mortality rate was $52.3 \%$.

Four (36.3\%) patients in Group I and $2(20 \%)$ patients in Group II $(p=0.534)$ underwent thrombectomy. Four of them (100\%, Group I) and 1 (50\%, Group II) additionally required bowel resection due to incomplete restoration of mesenteric blood flow after thrombectomy. Thrombectomy allowed 2 (25\%) patient in Group I and 1 patient (50\%) in Group II to recover $(p=0.673)$.

Intestinal resection for 5 (45.4\%) patients in Group I and 5 (50\%) patients in Group II ( $p=0.901)$ contributed to the recovery of $2(40 \%)$ patients in Group I and 2 (40\%) patients in Group II ( $p=1.000)$. In two cases of the first group, the general severity of the condition made the surgical treatment impossible $(p=0.194)$.

The authors assessed the correlation between mortality and the time of hospitalization. Four (50\%) out of eight patients who applied in the first $12 \mathrm{~h}, 2(66 \%)$ out of three in the first $12-24 \mathrm{~h}$, and $5(50 \%)$ out of 10 for more than $24 \mathrm{~h}$ had a positive treatment outcome in the combined group. 


\section{Logistic analysis}

A univariate and multivariate logistic regression analysis helped to determine the predictors of the planned treatment success and the type of thrombosis development. The initial parameters (partially displayed in Tables 1 and 2) determined the selection of predictor variables. Table 4 presents the predictor factors (univariate and multivariate logistic regression analysis).

The results helped to construct a model for predicting the recovery of the general group in multivariate regression analysis (predictor factors with a significance level of $p<0.5$ ). Age over 70 years became a significant predictor of the risk of death (OR $0.34 ; 95 \% \mathrm{Cl}-0.01 ; 0.7 ; \mathrm{p}=0.063)$, while other factors were not significant $(p>0.1)$. An independent predictor of recovery $(p<0.05)$ was the conservative approach (OR 2.3; 95\% Cl-0.0; 4.7; $p=0.050$ ), and clinical stages of necrosis and peritonitis became a significant predictor of the risk of death (OR 2.3; 95\% Cl-0.3; $4.4 ; p=0.023$ ). Consequently, the patient's age (over 70 years old) increases the risk of death by $34 \%$, the stage of necrosis and peritonitis has a 2.3 times higher probability of death, and only conservative therapy increases the chances of recovery by 2.3 times. Assessment of logit regression in both groups did not show significant predictors of recovery or death. The multivariate analysis logistic regression for determining the mesenteric thrombosis type did not show reliable predictors $(p<0.1)$.

The authors performed the statistical analysis of the overall survival rate. The Kaplan-Meier method estimates the survival rate of patients with nonocclusive ischemia, depending on the disease, duration was as follows: $77.7 \pm 13.8 \%$ with $95 \% \mathrm{Cl} 36.4-93.9 \%$ during the first $12 \mathrm{~h} ; 64.8 \pm 16.5 \%$ with $95 \% \mathrm{Cl}$ $25.3-87.2 \%$ within $12-24 \mathrm{~h}$; and $25.9 \pm 15.6 \%$ with $95 \% \mathrm{Cl} 3.8-57.0 \%$ within $24-48 \mathrm{~h}$. The survival rate of patients with the occlusive ischemia according to the Kaplan-Meier was as follows: $79.4 \pm 13.0 \%$ with $95 \%$ $\mathrm{Cl} 39.5-94.4 \%$ during the first $12 \mathrm{~h} ; 64.9 \pm 16.8 \%$ with $95 \% \mathrm{Cl} 24.6-87.5 \%$ within $12-24 \mathrm{~h}$; and $46.4 \pm 19.7 \%$ with $95 \% \mathrm{Cl} 10.2-77.2 \%$ within $24-48 \mathrm{~h}$. The log-rank criteria did not reveal the statistically significant survival rate difference in the comparison groups $(p=0.574)$, which is graphically presented by the Kaplan-Meier method (Figure 1).

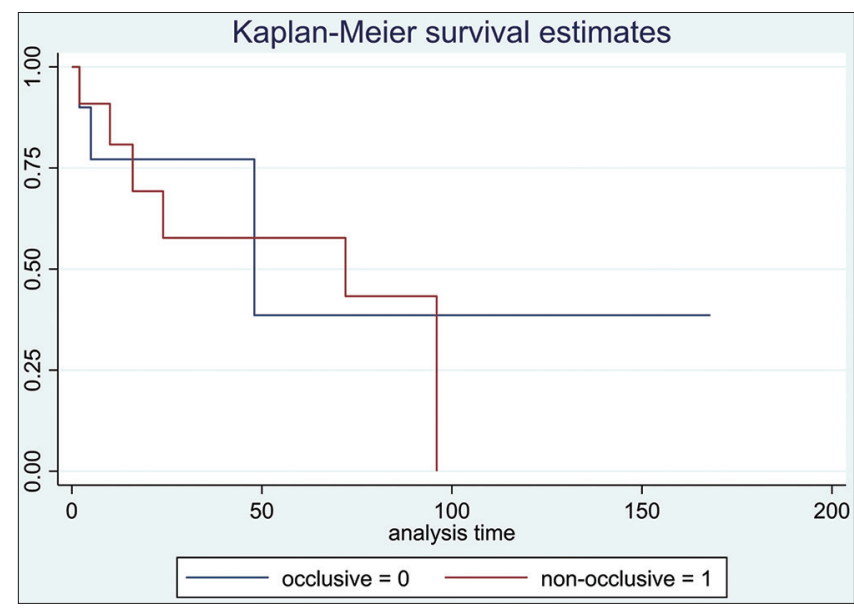

Figure 1: Patient survival prognosis in comparison groups, depending on the disease duration, expressed graphically by the Kaplan-Meier method

\section{Discussion}

The obtained results correlate with the data presented earlier in scientific publications. The occlusive form of the disease goes through three successive stages of development: The ischemia stage, which develops within a few minutes in the mucous and submucous layer; the infarction stage, which develops after about $6 \mathrm{~h}$ after occlusion; and the peritonitis stage. In the non-occlusive form of thrombosis, the period of necrosis development is a little longer up to $12 \mathrm{~h}$. It makes the timely diagnosis of the disease extremely important.

One of the main reasons for the development of mesenteric embolism is diseases with a risk of

Table 4: The mesenteric thrombosis type and the treatment success predictors

\begin{tabular}{|c|c|c|c|c|c|c|}
\hline \multirow[t]{2}{*}{ Source } & \multirow[t]{2}{*}{ Sign } & \multicolumn{3}{|c|}{ Univariate analysis } & \multicolumn{2}{|c|}{ Multivariate analysis } \\
\hline & & $\chi^{2}$ & OR $(95 \% \mathrm{Cl})$ & $\mathrm{p}$ & OR $(95 \% \mathrm{Cl})$ & $\mathrm{p}$ \\
\hline Clinical outcome, General group. & Over 70 years old & 8.0 & $-0.2(-0.4 ;-0.1)$ & 0.036 & $-0.34(-0.7 ; 0.01)$ & 0.063 \\
\hline \multirow{11}{*}{$\begin{array}{l}\text { Multivariate logit regression: } \chi^{2}=16.93 ; \\
p<0.001\end{array}$} & Stroke & 1.24 & $-1.02(-3.0 ; 0.8)$ & 0.279 & - & - \\
\hline & Erythrocytosis & 2.33 & $-1.3(-3.2 ; 0.4)$ & 0.138 & - & - \\
\hline & Proteinuria & 4.25 & $-1.9(-3.9 ;-0.03)$ & 0.054 & - & - \\
\hline & Fibrinogen $<2 \mathrm{GV}$ & 2.74 & $-1.5(-3.5 ; 0.3)$ & 0.115 & - & - \\
\hline & Hyperamylasemia & 2.89 & $-1.8(-4.3 ; 0.5)$ & 0.123 & - & - \\
\hline & Only conservative therapy & 5.07 & $2.3(-0.0 ; 4.7)$ & 0.050 & $1.7(-1.9 ; 5.5)$ & 0.344 \\
\hline & Thromboembolectomy & 1.24 & $-1.0(-3.0 ; 0.8)$ & 0.279 & - & - \\
\hline & Bowel resection & 1.18 & $-0.9(-2.7 ; 0.7)$ & 0.283 & - & - \\
\hline & Ischemia of the jejunum & 2.13 & $-1.6(-4.0 ; 0.7)$ & 0.182 & - & - \\
\hline & Occlusal type & 2.43 & $-1.4(-3.2 ; 0.4)$ & 0.131 & - & - \\
\hline & Stages of necrosis and peritonitis & 6.17 & $-2.3(-4.4 ;-0.3)$ & 0.023 & $-3.2(-7.5 ; 1.0)$ & 0.140 \\
\hline \multirow{8}{*}{$\begin{array}{l}\text { Mesenteric thrombosis type. } \\
\text { Multivariate logit regression: } \chi^{2}=7.7 \text {; } \\
p<0.02\end{array}$} & Obesity & 5.35 & $-0.1(-0.2 ; 0.005)$ & 0.064 & $-0.1(-0.2 ; 0.2)$ & 0.109 \\
\hline & Treatment in the first 6 hours of illness & 1.24 & $-1.09(-3.0 ; 0.88)$ & 0.279 & - & - \\
\hline & Diabetes & 2.44 & $-1.5(-3.4 ; 0.46)$ & 0.135 & - & - \\
\hline & Proteinuria & 2.33 & $1.38(-0.4 ; 3.2)$ & 0.138 & - & - \\
\hline & Microhematuria & 3.47 & $-2.0(-4.3 ; 0.36)$ & 0.097 & $-1.8(-4.3 ; 0.7)$ & 0.160 \\
\hline & Coagulopathy & 1.24 & $1.09(-0.8 ; 3.0)$ & 0.279 & - & - \\
\hline & Hypochloremia & 2.13 & $1.6(-0.7 ; 4.0)$ & 0.182 & - & - \\
\hline & Hypocalcemia & 1.31 & $-1.0(-2.8 ; 0.7)$ & 0.262 & - & - \\
\hline
\end{tabular}


thrombosis and vascular bed damage, such as cardiac pathologies such as atrial and ventricular fibrillation and/or flutter, myocardial infarction, cardiac and atherosclerosis, endocarditis, rheumatic defects, diabetes, and renal failure [8]. The reasons for the development of mesenteric vein thrombosis may be the purulent processes in the abdominal cavity, leading to the development of pylephlebitis, mechanical factors (adhesions of the abdominal cavity, infringement of the mesentery of the small and large intestines), blood diseases (polycythemia and thrombocytosis), sepsis, malignant neoplasms of the abdominal cavity, and others [4], [9]. Consequently, in a group of patients over 70 years old, in most cases, one or more predictors of the disease can give the reason to suspect mesenteric ischemia.

AMI diagnosis includes the patient complaints and anamnesis, an objective examination, and additional research methods (ultrasound of the abdominal organs and mesenteric vessels, X-ray of the abdominal organs, the mesenteric vessels angiography, and MSCT angiography) [3]. Unfortunately, there is still no specific marker of mesenteric ischemia [3]. However, the timely, routine MSCT angiography in most cases allows establishing the correct diagnosis.

The symptoms of this disease are very nonspecific. The main symptoms are severe pain (absent in $20 \%$ of cases) in the abdomen [4], [10], nausea $(93 \%)$, vomiting $(80 \%)$, diarrhea $(48 \%)$, and general weakness [11]. AMI can be unclear or proceed under the guise of other diseases of the abdominal organs so the diagnosis of this pathology is very difficult [12]. The long-term pain without obvious signs of surgical pathology is a reason to suspect mesenteric vessels thrombosis [13].

Radiography and ultrasound of the abdominal organs at the initial stages of the pathological process do not give clear information [14]. Only in the last stages of AMI, the roentgenogram can detect signs of intestinal obstruction. Good equipment and a highly qualified ultrasound specialist can help to assess the blood flow of the mesenteric vessels (the degree of vascular stenosis and the presence of lumen occlusion). A more informative research method is the angiography of the mesenteric vessels. However, since the procedure is invasive, it is difficult for patients in serious condition. MSCT angiography has several advantages: It is a non-invasive procedure with very high sensitivity (up to $90 \%$ ), not inferior to selective angiography (up to $88 \%$ ), and high specificity [2], [15]. An auxiliary significant diagnostic method is laparoscopy. It is most informative for severe ischemia (infarction), but not very effective at the early stages of the disease and in non-occlusive forms. The sensitivity and accuracy of laparoscopy in the diagnosis of mesenteric thrombosis are up to 90\% [16], [17].

Treatment of AMI includes conservative methods [18], [19], [20] with the infusion therapy [21], vasoactive, antioxidants, anti-enzymes, antibacterial [22], and anticoagulants [23], as well as surgical methods [3]. More effective methods of modern treatment include endovascular surgery and open thromboembolectomy [19], [20], [24]. Endovascular surgery includes internal angioplasty with or without stenting [25], catheter thromboembolectomy [26], and mesenteric vascular thrombolysis [27]. Nonviable areas of the intestine need resection according to the general surgery. Given the lack of absolute confidence that the blood supply within the boundaries of the resection is sufficient, there is a need to perform obstructive resection with a programmed "secondlook" - laparotomy/laparoscopy [28]. It is important to note that timely verification of the diagnosis allows the use of conservative or minimally invasive treatment, which significantly improves the prognosis of treatment in elderly patients. In comparison, the use of serious surgical interventions, such as restoration of blood flow through the vessels of the mesentery (with open or endovascular thromboembolectomy at the stage of ischemia); removal of segments of the intestine with irreversible changes (at the stage of necrosis and peritonitis) [3], [18], [19], [24], [28].

The prognosis for life and recovery remains unfavorable, and the mortality rate is 50-89\% [4], [7], [10].

The main patients' complaints in study were pain in the abdominal projection, nausea, vomiting, diarrhea, and general weakness, which are fully consistent with the results of the previous studies [4], [10], [11], [29].

The authors evaluated the diagnostic methods' efficiency. The ultrasound and plain radiography of the abdominal organs did not contribute to the establishment of the correct diagnosis. At the same time, the MSCT angiography made it possible to establish the correct diagnosis and determine the optimal treatment tactics [14]. This allows us to recommend MSCT angiography as a routine diagnostic technique for suspected acute bowel disease for elderly patients, even at the initial stage.

Logistic regression analysis did not show significant predictors for most of the factors assessed, probably due to the small size of the enrolled patients. Age factor (over 70 years old), the necrosis, and peritonitis stage became significant factors in the development of a negative (lethal) outcome of treatment.

Monoconservative therapy had a protective effect. However, these results require a deeper assessment of a larger sample, since the presented sample size was not enough to represent smaller statistical subgroups (those who applied in the first $6 \mathrm{~h}$ of illness; grading according to the degree of ischemia, etc.). Nevertheless, the obtained data are consistent with the results of other authors [10], [30], [31], [32]. For example, elderly patients with age greater or equal to 70 years was associated with a greater mortality rate $(43 \%)$ when compared with those younger than 
70 years of age $(23 \%, P=.01)$. No difference in the ischemic time was noted in the elderly patient cohort, which was $17 \pm 6.3$ hours, when compared with the ischemic time of $16 \pm 8.7$ hours in those younger than 70 years of age [30]

The authors assessed the mortality rate. This study did not show a significant difference and correlation between mortality and the time of hospitalization, which contradicts some data [33], [34]: $43 \%$ within $12 \mathrm{~h}, 56 \%$ within $12-24 \mathrm{~h}$, and $18 \%$ within more than $24 \mathrm{~h}$. It is possible to conclude that the mandatory MSCT angiography made it possible to more accurately verify the diagnosis and choose the correct primary treatment tactics, regardless of the timing of the disease. The overall mortality in our study corresponds to the results of other authors - 38-84\% [7], [10], [35]. A significant conclusion is a similar $(p=0.574)$ survival rate regardless of the ischemia type (with or without occlusion) with timely treatment, but no later than 2 days from the onset of the disease.

\section{Conclusion}

Mesenteric vascular thrombosis is a disease with an extremely high mortality rate (up to $90 \%$ ), for a reliable diagnosis, early MSCT angiography is the only specific diagnostic technique in all unclear or controversial clinical cases accompanied by constant abdominal pain, possibly nausea, vomiting, and diarrhea. The disease requires a complex combined conservative and, in most cases, surgical treatment. A laparoscopy or laparotomy is a mandatory evaluation procedure. The choice of the type and volume of therapeutic measures depend on the stage of ischemic disorders and may include conservative therapy, thromboembolectomy, and bowel resection. In some cases, it is necessary to perform obstructive bowel resection with subsequent secondlook programmatic assessment of the intestinal condition. The age over 70 years, peritoneal symptoms, and intestinal necrosis are extremely unfavorable prognostic signs.

\section{References}

1. Acosta S. Epidemiology of mesenteric vascular disease: Clinical implications. Semin Vasc Surg. 2010;23(1):4-8. PMid:20298944

2. POX. Acute Mesenteric Ischemia. National Clinical Guidelines APR 6. Available from: http://www.xn---9sbdbejx7bdduahou3a5d.xn--p1ai/stranica-pravlenija/ klinicheskie-rekomendaci/ostraja-mezenterialnaja-ishemija-nkr. $\mathrm{html}$;2018. [Last accessed on 2021 Jan 12].

3. Tilsed JV, Casamassima A, Kurihara H, Mariani D, Martinez I,
Pereira J, et al. ESTES guidelines: Acute mesenteric ischemia. Eur J Trauma Emerg Surg. 2016;42(2):253-70. https://doi. org/10.1007/s00068-016-0634-0

\section{PMid:26820988}

4. Haga Y, Odo M, Homma M, Komiya K, Takeda K, Koike S, et al. New prediction rule for mortality in acute mesenteric ischemia. Digestion. 2009;80(2):104-11. https://doi. org/10.1159/000219367

PMid:19556795

5. Krichevskaya GI, Slepova OS, Sahakyan SV, Myakoshina EB, Denisova YV. On the role of infections in the pathogenesis of retinoblastoma. Russ Ophthalmol J. 2013;6(2):37-40.

6. Berland T, Oldenburg WA. Acute mesenteric ischemia. Curr Gastroenterol Rep. 2008;10:341-6. https://doi.org/10.1007/ s11894-008-0065-0

7. Tsai MS, Lin CL, Chen HP, Lee PH, Sung FC, Kao CH. Longterm risk of mesenteric ischemia in patients with inflammatory bowel disease: A 13-year nationwide cohort study in an Asian population. Am J Surg. 2015;210(1):80-6. https://doi. org/10.1016/j.amjsurg.2014.08.026

PMid:25457233

8. Vokurka J, Olejnik J, Jedlicka V, Vesely M, Ciernik J, Paseka T. Acute mesenteric ischemia. Hepatogastroenterology. 2008;55:1349-52.

9. Atayan AA, Kandaurov AE, Kosenkov AN, Khachatryan EO, Belykh EN, Kirsanova EV, et al. Cardiac arrhythmia as a risk factor for acute mesenteric ischemia. Bull Dagestan State Med Acad. 2019;1:47-52.

10. Aouini F, Bouhaffa A, Baazaoui J, Khelifi S, Houas N, Cherif A. Acute mesenteric ischemia: Study of predictive factors of mortality. Tunis Med. 2012;90:533-6.

\section{PMid:22811227}

11. Dewitte A, Biais M, Coquin J, Fleureau C, Cassinotto C Ouattara $A$, et al. Diagnosis and management of acute mesenteric ischemia. Ann Fr Anesth Reanim. 2011;30:410-20.

12. Skorinova KD, Kuzmenko VV, Vasilenko IA. The prospect of creating medicines based on selenium nanoparticles (Review). Drug Dev Registr. 2020;9(2):33-44. https://doi. org/10.33380/2305-2066-2020-9-2-33-44

13. Brandt LJ, Boley SJ. AGA technical review on intestinal ischemia. American gastrointestinal association. Gastroenterology. 2000;118(5):954-68. https://doi.org/10.1016/ s0016-5085(00)70183-1 PMid:10784596

14. Oliva IB, Davarpanah AH, Rybicki FJ, Desjardins B, Flamm SD, Francois $\mathrm{CJ}$, et al. ACR appropriateness criteria ${ }^{\circledR}$ imaging of mesenteric ischemia. Abdom Imag. 2013;38:714-9. https://doi. org/10.1007/s00261-012-9975-2

15. Yikilmaz A, Karahan OI, Senol S, Tuna IS, Akyildiz HY. Value of multislice computed tomography in the diagnosis of acute mesenteric ischemia. Eur J Radiol. 2011;80(2):297-302. https:// doi.org/10.1016/j.ejrad.2010.07.016 PMid:20719444

16. Maksimenko MB, Tylocin IO, Petrus VG. Standard for the diagnosis of acute intestinal vascular insufficiency in a multidisciplinary clinic. Eur Res. 2017;2:97-101.

17. Komarov TN, Shohin IE, Miskiv OA, Bogdanova DS, Aleshina AV, Medvedev YV, et al. Development and validation of atazanavir and ritonavir determination in human plasma by HPLC-MS method. Drug Dev Registr. 2020;9(1):99-108. https:// doi.org/10.33380/2305-2066-2020-9-1-99-108

18. Neroyev VV, Saakian SV, Miakoshina EB, lurovskaia NN Riabina MV, Zaĭtseva OV, et al. Differential diagnosis of early central choroidal melanoma and late stage age-related macula degeneration. Vestnik Oftalmol. 2013;129(1):39-45. 


\section{PMid:23650747}

19. Aboyans V, Ricco JB, Bartelink ML, Bjorck M, Brodmann M, Cohnert T, et al. 2017 ESC guidelines on the diagnosis and treatment of peripheral arterial diseases, in collaboration with the European society for vascular surgery (ESVS): Document covering atherosclerotic disease of extracranial carotid and vertebral, mesenteric, renal, upper and lower extremity arteries endorsed by: The European stroke organization (ESO) the task force for the diagnosis and treatment of peripheral arterial diseases of the European society of cardiology (ESC) and of the European society for vascular surgery (ESVS). Eur Heart J. 2018;39:763-816. https://doi. org/10.15829/1560-4071-2018-8-164-221

PMid:28886620

20. Bala M, Kashuk J, Moore EE, Kluger Y, Biffl W, Gomes CA, et al. Acute mesenteric ischemia: Guidelines of the world society of emergency surgery. World J Emerg Surg. 2017;12:1-14. https:// doi.org/10.1186/s13017-017-0150-5 PMid:28794797

21. Trineeva OV, Gudkova AA, Rudaya MA. Application of luminescent microscopy in analysis of anatomic-diagnostic signs of fruits of sea buckthorn. Drug Dev Registr. 2020;9(1):40-5. https://doi.org/10.33380/2305-2066-2020-9-1-40-45

22. Wong PF, Gilliam AD, Kumar S, Shenfine J, O'Dair GN Leaper DJ. Antibiotic regimens for secondary peritonitis of gastrointestinal origin in adults. Cochrane Database Syst Rev. 2005;2:CD004539. https://doi.org/10.1002/14651858. cd004539.pub2

PMid:15846719

23. Yanar F, Ağcaoğlu O, Gök AF, Sarici IS, Ozcinar B, Aksakal N, et al. The management of mesenteric vein thrombosis: A single institution's experience. Ulus Travma Acil Cerrahi Derg. 2013;19(3):223-8. https://doi.org/10.5505/tjtes.2013.47542 PMid:23720109

24. Becquemin JP. Management of the diseases of mesenteric arteries and veins: clinical practice guidelines of the European society for vascular surgery (ESVS). Eur J Vasc Endovasc Surg. 2017;53(4):455-7. https://doi.org/10.1016/j.ejvs.2018.09.006 PMid:28359439

25. Jia Z, Jiang G, Tian F, Zhao J, Li S. Wang K, et al. Early endovascular treatment of superior mesenteric occlusion secondary to thromboemboli. Eur J Vasc Endovasc Surg. 2014;47(2):196-203. https://doi.org/10.1016/j.ejvs.2013.09.025 PMid:24183620

26. Kim BG, Ohm JY, Bae MN, Kim HN, Kim YJ, Chung MH, et al. Successful percutaneous aspiration thrombectomy for acute mesenteric ischemia in a patient with atrial fibrillation despite optimal anticoagulation therapy. Can J Cardiol. 2013;29(10):1329-36. https://doi.org/10.1016/j. cjca.2012.12.008

PMid:23465342

27. Simó G, Echenagusia AJ, Camúñez F, Turégano F, Cabrera $A$, Urbano J. Superior mesenteric arterial embolism: Local fibrinolytic treatment with urokinase. Radiology. 1997;204(3):775-9. https:// doi.org/10.1148/radiology.204.3.9280258

PMid:9280258

28. Acosta S, Björck M. Modern treatment of acute mesenteric ischaemia. Br J Surg. 2014;101(1):100-8. PMid:24254428

29. Sreedharan S, Tan YM, Tan SG, Soo KC, Wong WK. Clinical spectrum and surgical management of acute mesenteric ischaemia in Singapore. Singapore Med J. 2007;48(4):319-23. PMid: 17384879

30. Kougias P, Lau D, El Sayed HF, Zhou W, Huynh TT, Lin PH. Determinants of mortality and treatment outcome following surgical interventions for acute mesenteric ischemia. J Vasc Surg. 2007;46(3):467-74. https://doi.org/10.1016/j. jvs.2007.04.045

PMid: 17681712

31. Edwards MS, Cherr GS, Craven TE, Olsen AW, Plonk GW, Geary RL, et al. Acute occlusive mesenteric ischemia: Surgical management and outcomes. Ann Vasc Surg. 2003;17(1):72-9. https://doi.org/10.1007/s10016-001-0329-8 PMid:12522695

32. Wadman M, Syk I, Elmståhl S. Survival after operations for ischaemic bowel disease. Eur J Surg. 2000;166(11):872-7. PMid: 11097154

33. Lobo Martínez E, Meroño Carvajosa E, Sacco O, Molina EM Embolectomy in mesenteric ischemia. Rev Esp Enferm Dig. 1993;83(5):351-4. PMid:8318278

34. Eltarawy IG, Etman YM, Zenati M, Simmons RL, Rosengart MR. Acute mesenteric ischemia: The importance of early surgical consultation. Am Surg. 2009;75(3):212-9. https://doi. org/10.1177/000313480907500305 PMid: 19350855

35. Aliosmanoglu I, Gul M, Kapan M, Arikanoglu Z, Taskesen F, Basol $\mathrm{O}$, et al. Risk factors effecting mortality in acute mesenteric ischemia and mortality rates: A single center experience. Int Surg. 2013;98(1):76-81. https://doi.org/10.9738/cc112.1 PMid:23438281 